\title{
Analysis of correlation between the detection rate of Mycoplasma hyopneumoniae in slaughter pigs and season, climate change, and presence of lung lesions")
}

\author{
RUNCHENG LI, YULI HU, MENG GE, DUN ZHAO, \\ TAOTAO YANG, RENKE QING, XINGLONG YU
}

College of Veterinary Medicine, Hunan Agricultural University, Changsha, China

Li R.C., Hu Y.L., Ge M., Zhao D., Yang T.T., Qing R.K., Yu X.L.

Analysis of correlation between the detection rate of Mycoplasma hyopneumoniae in slaughter pigs and season, climate change, and presence of lung lesions

\section{Summary}

The purpose of this study was to analyze the correlation of the rate of Mycoplasma hyopneumoniae (M. hyo) in slaughter pigs with season, climate change and enzootic pneumonia (EP) lesions. We collected 530 slaughter pig lungs with suspected lesions from two slaughterhouses in different seasons and weather conditions from November 2014 to March 2017 in Changsha Hunan Province, China. The EP lesions of these lungs were quantified, and a PCR analysis was used to detect M. hyo in samples of bronchoalveolar lavage fluid (BALF). Twenty percent, $10 \%$, and $9 \%$ of the lung specimens were scored 1-5, 6-10, and $\geq 11$, respectively. Additionally, we found that $36 \%$ of all BALF samples tested positive for M. hyo. Among the lung specimens collected in winter, $41 \%$ scored 1 or more, and $53 \%$ tested positive for $M$. hyo. With respect to seasons, the lung specimens collected in summer showed the least number of EP lesions and the lowest positive testing rate for M. hyo. Of these specimens, $27 \%$ scored 1 or more, and $22 \%$ tested positive for M. hyo. Additionally, low temperature and fast temperature change (during 10 days before sampling) were associated with a higher rate of $M$. hyo detection in BALF. There was a positive correlation between the lung EP lesion score and the detection rate of M. hyo in the BALF of slaughter pigs. In conclusion, lung EP lesion scoring in slaughter pigs is of referential value to the evaluation of the dynamics of $M$. hyo infection in a swine population. It is essential to control the spread of M. hyo by careful management of swine populations, and the prevention and control of M. hyo in fattening pigs is of great significance to the eradication of the disease.

Keywords: slaughter pigs, bronchoalveolar lavage fluid, Mycoplasma hyopneumoniae, seasons, China

Mycoplasma hyopneumoniae (M. hyo) is widely distributed around the world, and it is the principal etiological agent for enzootic pneumonia (EP), a chronic respiratory disease that affects primarily finishing pigs. EP can lead to decreased growth rate and feed conversion efficiency (18). The severity of clinical signs increases after infection with secondary bacteria $(1,3)$. This condition can lead to enormous economic losses for pig farmers. Vaccination against $M$. hyo infections has been extensively proven to be effective in reducing the clinical signs and lung lesions associated with $M$. hyo infection. However, vaccination cannot fully prevent the transmission of $M$. hyo within

This work was supported by the National Key Research and Development Program of China (2017YFD0500102). a swine population $(9,11,21)$. The objective of the present study was to analyze the correlation between the detection rate of $M$. hyo in slaughter pigs with the presence of lung EP lesions and changes in season and climate, and consequently to provide a reference for the diagnosis and control of $M$. hyo infection in finishing pigs.

\section{Material and methods}

Samples. Two abattoirs were selected for this study (one abattoir processed 2000 pigs daily from various pig farms in Hunan Province, China). During each visit to the abattoirs, one hundred lungs of slaughter pigs were randomly collected from the flow line, and approximately twenty lungs with suspected serious lesions (a ratio of $\sim 20 \%$ ) were 
selected for further investigation. In total, five hundred and thirty lungs with suspected lesions were collected from the two slaughterhouses in differ-

Tab. 1. EP lesions observed in lungs and detection of $M$. hyo in BALF

\begin{tabular}{|l|r|c|c|c|c|c|c|c|c|c|c|}
\hline EP lesion score (points) & \multicolumn{1}{|c|}{0} & 1 & 2 & 3 & 4 & 5 & 6 & $7-8$ & $9-10$ & $11-15$ & $16-26$ \\
\hline Number & 321 & 24 & 29 & 22 & 18 & 15 & 18 & 19 & 16 & 21 & 27 \\
Rate of $\boldsymbol{M}$. hyo (\%) & 24 & 25 & 45 & 59 & 44 & 73 & 56 & 74 & 63 & 71 & 71 \\
\hline
\end{tabular}

ent seasons and weather conditions from November 2014 to March 2017 in Changsha Hunan Province, China. An M. hyo-positive control sample was identified and stored by the veterinary laboratory of Hunan Agricultural University, China (GenBank accession number: KY696715).

Climate during 10 days before sampling. To analyse the influence of sudden changes in climatic environment on the detection rate of $M$. hyo, climatic data were recorded for 10 days before sampling (22). To assess the temperature range between day and night, or between different dates, the coefficient of variation of temperature was calculated based on daily maximum and minimum air temperatures.

Scoring. After the lungs had been collected from the abattoirs, they were transported to a veterinary laboratory and scored by the same veterinarian according a scoring system previously described $(10,13)$. According to that scoring system, each lobe of a lung was assigned 0-4 points depending on the percentage of the lobe affected by EP lesions. A lobe was assigned 4 points if EP lesions affected three-quarters of the surface of the lobe. The final lung score was the sum of scores given to each of the seven lung lobes.

Treatment of lungs. Bronchoalveolar lavage was performed on each lung specimen with $20 \mathrm{ml}$ of sterilized phosphate-buffered saline (PBS), and the bronchoalveolar lavage fluid (BALF) was collected and stored at $-20^{\circ} \mathrm{C}$.

Extraction of DNA. According to the extraction protocol, $3 \mathrm{ml} \mathrm{BALF}$ was taken from each lung and centrifuged at $12000 \mathrm{rpm}$ for 5 minutes at $4^{\circ} \mathrm{C}$. The precipitation was resuspended in $100 \mu \mathrm{l}$ PBS. DNA extraction of the precipitation suspension was performed using a commercial DNA extractor kit (TaKara Biomedical Technonlogy, Beijing, China) following the manufacturer's instructions. The extracted DNA was stored at $-20^{\circ} \mathrm{C}$.

PCR assay. A conventional PCR was employed to amplify a fragment of the P46 gene of $M$. hyo from the BALF. The assay was performed using primers (previously reported) (2) in a $20 \mu \mathrm{l}$ reaction mixture containing $10 \mu \mathrm{l} 2 \times$ Multiplex PCR Master Mix (TransGen Biotech, Beijing, China), $1.0 \mu 1$ DNA extracted from BALF, $0.6 \mu \mathrm{l}$ primers mix, and $8.4 \mu \mathrm{l}$ double-distilled water. The conditions of the PCR assays were as follows: initial denaturation at $94^{\circ} \mathrm{C}$ for $7 \mathrm{~min}$ followed by 30 amplification cycles $\left(94^{\circ} \mathrm{C}\right.$ for $30 \mathrm{sec}, 50^{\circ} \mathrm{C}$ for $30 \mathrm{sec}$, and $72^{\circ} \mathrm{C}$ for $30 \mathrm{sec}$ ) and a final extension cycle at $72^{\circ} \mathrm{C}$ for $7 \mathrm{~min}$.

Statistical analysis. The average temperature and the coefficient of temperature variation during the 10 days before each sampling were calculated on the basis of meteorological data recorded in the areas of origin of the pigs slaughtered, and lung analyses were performed. Correlation analysis (relationship between the rate of $M$. hyo and the season; relationship between the rate of $M$. hyo and the air temperature; relationship between lung EP lesion scores and the air temperature; relationship between the rate of $M$. hyo and the EP lesion score) was performed by chi-square tests or $r$ values using SPSS software version 19.0 (IBM Inc., Chicago, IL, USA). The results were considered significant at $\mathrm{P}<0.05$.

Tab. 2. EP lesion scores and M. hyo-positive rates for lungs collected in different seasons

\begin{tabular}{|l|c|c|c|c|}
\hline \multicolumn{1}{|c|}{ Sampling time } & Winter $^{\text {a) }}$ & Spring $^{\text {b) }}$ & Summer $^{\text {c) }}$ & Autumn $^{\text {d) }}$ \\
\hline Number of lungs & 128 & 140 & 82 & 180 \\
$\begin{array}{l}\text { Percentage of lungs with } \\
\text { a score of } 1 \text { or more }\end{array}$ & $41 \%$ & $53 \%$ & $27 \%$ & $33 \%$ \\
\begin{tabular}{l} 
Rate of $M$. hyo in BALF \\
\hline
\end{tabular} & $53 \%$ & $46 \%$ & $22 \%$ & $24 \%$ \\
\hline
\end{tabular}

Explanations: a - December, January, and February; b - March, April, and May; c - June, July, and August; d - September, October, and November

\section{Results and discussion}

Lung selection and EP lesion scoring. In this study, 530 lungs that were suspected to have lesions were collected from November 2014 to March 2017 and assigned an EP lesion score according to a scoring system previously described $(10,13)$. Of these, 209 lungs were found to have significant EP lesions. Among them, 108 lungs were given a score of $1-5$, which accounted for $20 \%$ of the total group. Additionally, 53 lungs (10\%) were scored 6-10, and 48 lungs $(9 \%)$ were assigned a score of 11 or more (Tab. 1).

PCR detection of $M$. hyo. The P46 gene of M. hyo in DNA from BALF was detected by conventional PCR. The results showed there were 194 BALF-positive tests for $M$. hyo, and the total positive rate for $M$. hyo was $36.6 \%$. The highest positive test rate for $M$. hyo was obtained from BALF samples collected in winter (December, January, and February), followed by BALF from lungs collected in spring (March, April, and May). The lowest rates were detected in BALF collected in summer (June, July, and August) (Tab. 2). The positive rate for $M$. hyo in BALF collected at different times ranged from $0-85 \%$ (Tab. 3).

Relationship between the rate of $M$. hyo and season. The lungs collected in different seasons showed different positive test rates for $M$. hyo in BALF. The positive test rates for $M$. hyo in BALF samples collected in winter and spring were significantly higher than in BALF samples collected in summer or autumn $(\mathrm{P}<0.001)$. There were no significant differences between the $M$. hyo-positive test rates in BALF samples collected in the summer and autumn months $(\mathrm{P}=0.731)$.

Relationship between the rate of $M$. hyo and atmospheric temperature. The atmospheric temperature was recorded during the 10 days before sampling, and the average temperature and the coefficient of temperature variation ( $\mathrm{VC}$ of atmospheric temperature) were calculated. Additionally, we calculated the rate of $M$. hyo in BALF and the average score of EP lesions in the lungs. Statistical analysis results indicated that faster temperature changes (VC of atmospheric temperature) were correlated with a higher $M$. hyo detection rate in 
Tab. 3. Relationship between atmospheric temperature, lung EP lesions, and the rate of $M$. hyo

\begin{tabular}{|c|c|c|c|c|c|}
\hline \multirow[b]{2}{*}{ Sampling time } & \multicolumn{2}{|c|}{$\begin{array}{l}\text { Temperature during } 10 \text { days } \\
\text { before sampling }\end{array}$} & \multirow{2}{*}{$\begin{array}{c}\text { Average } \\
\text { lung EP } \\
\text { lesion } \\
\text { score } \\
\text { (points) }\end{array}$} & \multirow{2}{*}{$\begin{array}{c}\text { Percentage } \\
\text { of lungs } \\
\text { with EP } \\
\text { lesions } \\
(\%)\end{array}$} & \multirow{2}{*}{$\begin{array}{c}\text { Rate of } \\
\text { M. hyo } \\
\text { in BALF } \\
(\%)\end{array}$} \\
\hline & $\begin{array}{c}\text { Average } \\
\text { temperature } \\
\left({ }^{\circ} \mathrm{C}\right) \\
\end{array}$ & $\begin{array}{c}\text { Coefficient } \\
\text { of variation }{ }^{a)} \\
(\%)\end{array}$ & & & \\
\hline 3 February, 2015 & 5.60 & 97 & 5.90 & 80 & 70 \\
\hline 18 January, 2016 & 5.82 & 48 & 6.80 & 57 & 52 \\
\hline 28 December, 2015 & 7.36 & 39 & 0.80 & 31 & 38 \\
\hline 2 February, 2017 & 8.17 & 63 & 0.57 & 9 & 22 \\
\hline 12 January, 2017 & 9.17 & 43 & 0.72 & 25 & 57 \\
\hline 23 December, 2016 & 9.36 & 74 & 2.20 & 50 & 75 \\
\hline 2 December, 2015 & 9.83 & 40 & 3.60 & 47 & 59 \\
\hline 24 March, 2017 & 10.62 & 23 & 4.24 & 81 & 71 \\
\hline 3 March, 2017 & 10.78 & 49 & 4.95 & 67 & 67 \\
\hline 2 March, 2016 & 11.67 & 48 & 0.04 & 4 & 0 \\
\hline 25 November, 2016 & 11.95 & 58 & 8.59 & 70 & 5 \\
\hline 10 March, 2017 & 12.10 & 31 & 6.87 & 91 & 74 \\
\hline 25 November, 2014 & 13.64 & 26 & 1.20 & 25 & 35 \\
\hline 24 March, 2016 & 13.91 & 29 & 0.00 & 0 & 0 \\
\hline 13 November, 2015 & 14.91 & 34 & 9.70 & 90 & 85 \\
\hline 15 October, 2015 & 20.50 & 21 & 0.80 & 10 & 16 \\
\hline 27 May, 2016 & 20.59 & 13 & 6.25 & 50 & 15 \\
\hline 29 October, 2015 & 21.23 & 26 & 0.20 & 15 & 37 \\
\hline 9 October, 2016 & 21.90 & 5 & 0.86 & 33 & 0 \\
\hline 30 April, 2016 & 22.33 & 23 & 2.29 & 50 & 67 \\
\hline 17 September, 2015 & 25.55 & 22 & 0.40 & 25 & 35 \\
\hline 22 September, 2016 & 25.77 & 16 & 0.00 & 0 & 6 \\
\hline 13 June, 2016 & 26.12 & 20 & 0.10 & 10 & 10 \\
\hline 13 September, 2016 & 26.82 & 15 & 0.38 & 20 & 0 \\
\hline 13 August, 2015 & 29.73 & 14 & 5.60 & 47 & 32 \\
\hline 19 July, 2016 & 30.09 & 11 & 0.00 & 0 & 13 \\
\hline 13 August, 2016 & 30.14 & 11 & 2.60 & 55 & 35 \\
\hline
\end{tabular}

Explanations: $\mathrm{a}-$ coefficient of variation $=$ standard deviation of daily maximum and minimum temperature during 10 days before sampling/average value of daily maximum and minimum temperature during 10 days before sampling $\times 100 \%$.
Relationship between EP lesions of lungs and the rate of $M$. hyo. The lung EP lesion scores and the rate of $M$. hyo showed a strong positive correlation $(\mathrm{r}=0.7028$, $\mathrm{P}=0.016)$ (Tab. 1). It can be seen that in different batches of samples, there was a strong positive correlation between the positive testing rate for $M$. hyo in BALF and the average lung EP lesion score $(r=0.5068$, $\mathrm{P}=0.007$ ) or the percentage of lungs with EP lesions $(r=0.7326, P<0.001)($ Tab. 3$)$. The small number of inconsistent results may be attributed to lungs that were collected from pigs that had been vaccinated or grown on $M$. hyo-infected swine farms.

Our results indicated that there was a strong correlation between the detection rate of M. hyo in the BALF of slaughter pigs and the season, climate change, and amount of lung EP lesions present. The lungs collected in winter and spring (cold and damp seasons) had higher EP lesion scores and detection rates of $M$. hyo, whereas the lungs collected in summer (a dry season with high temperatures) had the lowest score and the lowest rate of $M$. hyo. Additionally, lower temperatures and faster temperature changes during the sampling period were associated with a higher positive testing rate for $M$. hyo in BALF. The main reason for the aforementioned relationship is that cold, wet, or low-temperature environments are more conducive to the survival of $M$. hyo (5, $7,15,20)$, which increases the probability of $M$. hyo transmission within the swine population. $M$. hyo are more likely to be inactivated in a dry and high-temperature environment (12). Furthermore, because of low temperatures, the windows of piggeries are opened less and for a shorter period (than they are under warm temperatures) so as to preserve heat; consequently, the respiratory tracts of pigs are more likely to be damaged by harmful gases, such as BALF $(r=0.4094, \mathrm{P}<0.05)$. The average atmospheric temperature (during 10 days before sampling) and the $M$. hyo detection rate in BALF showed a significant negative correlation $(\mathrm{r}=-0.461, \mathrm{P}<0.05)(\mathrm{Tab} .3)$.

Relationship between atmospheric temperature and lung EP lesions. The average temperature during the 10 days before each sampling and the percentage of lungs with EP lesions showed a marginally significant negative correlation $(\mathrm{r}=-0.3641, \mathrm{P}=0.062)$. However, the average temperature was not significantly correlated with average lung EP lesion scores $(r=-0.3151$, $\mathrm{P}=0.109$ ), and the coefficient of temperature variation during 10 days before each sampling was not significantly correlated with average lung EP lesion scores $(\mathrm{r}=0.2885, \mathrm{P}=0.144)$ or the percentage of lungs with EP lesions $(\mathrm{r}=0.3124, \mathrm{P}=0.113)$ (Tab. 3). $\mathrm{NH}_{3}$ or $\mathrm{H}_{2} \mathrm{~S}$, which may exceed the acceptable limit in piggeries. Therefore, the respiratory tracts of pigs are more susceptible to infection by $M$. hyo (6).

In this study, 209 lungs, accounting for 39.4\% of the total sample, showed significant EP lesions. The percentage of lungs with EP lesions was higher than that reported in another study $(23.85 \%)(12)$. This difference may be attributed to the fact that in the present study all lung specimens were selected because they were suspected to have lesions, whereas in the other study, the lungs were selected randomly. Tab. 1 shows that the BALF of $43.5 \%$ of lungs with EP lesions tested negative for $M$. hyo by the PCR test, whereas $23.7 \%$ of lungs without EP lesions tested positive. These results are similar to those reported in the literature (4). This can be explained by the fact that the evaluation of EP 
lesions only identifies chronic lung lesions at the end of the production period and does not provide information regarding the respiratory health problems of pigs during the fattening period (14). For example, the influenza virus, or concurrent infection with multiple pathogens, can cause lesions in the lung that mask EP lesions (4, 19). On the other hand, lesion resolution may lead to false-negative results or to an equivocal diagnosis in the early stage of $M$. hyo infection (17). Therefore, for a more accurate assessment of $M$. hyo infection in a herd, the use of additional confirmatory methods is needed (16). Nevertheless, the results of this study showed there was a strong positive correlation between the lung EP lesion score and the detection rate of $M$. hyo in BALF $(r=0.7028, P=0.016)$. Furthermore, Tab. 2 shows that the EP lesion rate was higher in the lungs collected in spring $(53 \%)$ than it was in those collected in winter (41\%). However, the $M$. hyo-positive rate for BALF samples was lower $(46 \%)$. One reason for this may be that some lungs sampled in spring came from pigs infected by $M$. hyo in early winter. Due to the immune response to infection, the content of $M$. hyo in the lungs was below the detection threshold of PCR at the time of slaughter. Nonetheless, EP lesions caused by $M$. hyo did not disappear completely $(8,17)$. This may imply that the air temperature during the 10 days before each sampling was not significantly correlated with the presence of lung EP lesions. A short period of poor or suitable climatic conditions may negatively or positively affect the immune function of pigs, which may lead to an increase or decrease in the amount of $M$. hyo in swine lungs. However, to confirm that unfavourable or favourable climatic conditions are capable of affecting pig lungs, longer study periods are required.

The results of this study show that there was a high $M$. hyo infection rate in slaughter pigs, and specimens of lungs with severe EP lesions were found after slaughter. It is implied that there was a high $M$. hyo infection rate in fattening pigs, which reduced their growth and feed conversion rates. The controlling or eradicating $M$. hyo was additionally complicated by the extensive spreading of $M$. hyo from the fattening pigs to other swine populations.

In conclusion, there was a strong correlation between the detection rate of $M$. hyo in the BALF of slaughter pigs and the season, climate change, and amount of lung EP lesions present. It is very important to control the spread of $M$. hyo by fine management of swine populations, including effective heat preservation, ventilation, and timely response to sudden climatic conditions. Although the current vaccine can help pigs acquire a certain degree of resistance, and thus improve their production performance $(9,23)$, it does not fully prevent the spread of $M$. hyo within the swine population, and it proved incapable of eradicating $M$. hyo $(9,11,21)$. Lung EP lesion scoring in slaughter pig is of referential value in evaluating the dynamics of $M$. hyo infection in swine population. Furthermore, the prevention and control of $M$. hyo in fattening pigs is essential for the eradication of the disease. To the best of our knowledge, this study is the first to analyze the detection rate of $M$. hyo in BALF from slaughtered pigs in relation to the season, climate, and presence of lung EP lesions, and the findings from this study have provided important data for understanding the diagnosis and control of $M$. hyo infection in a swine population.

\section{References}

1. Amass S. F., Clark L. K., van Alstine W. G., Bowersock T. L., Murphy D. A., Knox, K. E. and Albregts $S$. R.: Interaction of Mycoplasma hyopneumoniae and Pasteurella multocida infections in swine. J. Am. Vet. Med. Assoc. 1994, 204 102-107.

2. Caron J., Ouardani M., Dea S.: Diagnosis and differentiation of Mycoplasma hyopneumoniae and Mycoplasma hyorhinis infections in pigs by PCR amplification of the p36 and p46 genes. J. Clin. Microbiol. 2000, 38, 1390-1396.

3. Caruso J. P., Ross, R. F.: Effects of Mycoplasma hyopneumoniae and Actinobacillus (Haemophilus) pleuropneumoniae infections on alveolar macrophage functions in swine. Am. J. Vet. Res. 1990, 52, 227-231

4. Calsamiglia M., Collins J. E., Pijoan C.: Correlation between the presence of enzootic pneumonia lesions and detection of Mycoplasma hyopneumoniae in bronchial swabs by PCR. Vet. Microbiol. 2000, 76, 299-303.

5. Dee S., Otake S., Deen J.: Use of a production region model to assess the efficacy of various air filtration systems for preventing airborne transmission of porcine reproductive and respiratory syndrome virus and Mycoplasma hyopneumoniae: Results from a 2-year study. Virus. Res. 2010, 154, 177-184.

6. Donham K. J.: Association of environmental air contaminants with disease and productivity in swine. Am. J. Vet. Res. 1991, 52, 1723-1730.

7. Goodwin R. F.: Apparent reinfection of enzootic-pneumonia-free pig herds: search for possible causes. Vet. Record. 1985, 116, 690-694.

8. Fano E., Pijoan C., Dee S.: Dynamics and persistence of Mycoplasma hyopneumoniae infection in pigs. Can. J. Vet. Res. 2005, 69, 223-228.

9. Hillen S., Berg S. V., Köhler K., Reinacher M., Willems H., Reiner G.: Occurrence and severity of lung lesions in slaughter pigs vaccinated against Mycoplasma hyopneumoniae with different strategies. Prevent. Vet. Med 2014, 113, 580-588.

10. Madec F., Kobisch M.: Bilan lésionnel des poumons de porcs charcutiers à l'abattoir. Journ. Rech. Porc. Fr. 1982, 14, 405-412.

11. Meyns T., Dewulf J., Kruif A. D., Calus D., Haesebrouck F., Maes D.: Comparison of transmission of Mycoplasma hyopneumoniae in vaccinated and non-vaccinated populations. Vaccine 2006, 24, 7081-7086.

12. Meyns T., Steelant J. V., Rolly E., Dewulf J., Haesebrouck F., Maes D.: A crosssectional study of risk factors associated with pulmonary lesions in pigs at slaughter. Vet. J. 2011, 187, 388-392.

13. Morante B. G., Segales J., Fraile L., Perez de Rosas A., Maiti H., Coll T., Sibila M.: Assessment of Mycoplasma hyopneumoniae-induced pneumonia using different lung lesion scoring systems: A comparative review. J. Comp. Pathol. 2016, 154, 125-134.

14. Noyes E. P., Feeney D. A., Pijoan C.: Comparison of the effect of pneumonia detected during lifetime with pneumonia detected at slaughter on growth in swine. J. Am. Vet. Med. Assoc. 1990, 197, 1025-1029.

15. Otake S., Dee S., Corzo C., Oliveira S., Deen J.: Long-distance airborne transport of infectious PRRSV and Mycoplasma hyopneumoniae from a swine population infected with multiple viral variants. Vet. Microbiol. 2010, 145, 198-208.

16. Sibila M., Pieters M., Molitor T., Maes D., Haesebrouck F., Segales J.: Current perspectives on the diagnosis and epidemiology of Mycoplasma hyopneumoniae infection. Vet. J. 2009, 181, 221-231.

17. Sørensen V., Ahrens P., Barfod K., Feenstra A. A., Feld N. C., Friis N. F., BilleHansen $V$., Jensen N. E., Pedersen $M . W$.: Mycoplasma hyopneumoniae infection in pigs: Duration of the disease and evaluation of four diagnostic assays. Vet. Microbiol. 1997, 54, 23-34.

18. Straw B. E., Tuovinen V. K., Bigras-Poulin M.: Estimation of the cost of pneumonia in swine herds. J. Am. Vet. Med. Assoc. 1989, 195, 1702-1706.

19. Thacker E. L., Thacker B. J., Janke B. H.: Interaction between Mycoplasma hyopneumoniae and swine influenza virus. J. Clin. Microbiol. 2001, 39, 2525-2530 .

20. Vangroenweghe F. A. C. J., Labarque G. G., Piepers S., Minder K. S., Maes D. Mycoplasma hyopneumoniae infections in peri-weaned and post-weaned pigs in Belgium and the Netherlands: Prevalence and associations with climatic conditions. Vet. J. 2015, 205, 93-97.

21. Villarreal I., Meyns T., Dewulf J., Vranckx K., Calus D., Pasmans F., Haesebrouck F., Maes D.: The effect of vaccination on the transmission of Mycoplasma hyopneumoniae in pigs under field conditions. Vet. J. 2011, 188, 48-52.

22. Verhagen J. M. F.: Acclimation of growing pigs to climatic environment. Thesis, Wageningen, the Netherlands 1987, P. 111

23. Wilson S., Brussel L. V., Saunders G., Taylor L., Zimmermann L., Heinritzi K., Ritzmann M., Banholzer E., Eddicks M.: Vaccination of piglets at 1 week of age with an inactivated Mycoplasma hyopneumoniae vaccine reduces lung lesions and improves average daily gain in body weight. Vaccine 2012, 30, 7625-7629.

Corresponding author: XingLong Yu, Prof. Dr., College of Veterinary Medicine, Hunan Agricultural University, Changsha, China; e-mail: xlyu999@126.com 